\title{
Computational design of faster rotating second- generation light-driven molecular motors by control of steric effects
}

\author{
Baswanth Oruganti, Changfeng Fang and Bo Durbeej
}

Linköping University Post Print

Tweet

N.B.: When citing this work, cite the original article.

Original Publication:

Baswanth Oruganti, Changfeng Fang and Bo Durbeej, Computational design of faster rotating second-generation light-driven molecular motors by control of steric effects, 2015, Physical Chemistry, Chemical Physics - PCCP, (17), 33, 21740-21751.

http://dx.doi.org/10.1039/c5cp02303c

Copyright: Royal Society of Chemistry http://www.rsc.org/

Postprint available at: Linköping University Electronic Press

http://urn.kb.se/resolve?urn=urn:nbn:se:liu:diva-121153 


\title{
Computational design of faster rotating second-generation light-driven molecular motors by control of steric effects $\uparrow$
}

\author{
Baswanth Oruganti, $\ddagger^{\mathrm{a}}$ Changfeng Fang $\ddagger^{\mathrm{ab}}$ and Bo Durbej*a \\ ${ }^{a}$ Division of Theoretical Chemistry, IFM, Linköping University, SE-581 83 Linköping, Sweden \\ ${ }^{b}$ Department of Physics, Jining University, Qufu 273155, China
}

\footnotetext{
$\dagger$ Electronic Supplementary Information (ESI) available: Supplementary computational methods, Figs. S1 and S2, Tables S1-S14, and Cartesian coordinates of stationary points.

\$ These two authors contributed equally to this work and are co-first authors.

* Corresponding author. Tel: 46-13-282497. Fax: 46-13-137568. E-mail: bodur@ifm.liu.se.
} 


\begin{abstract}
We report a systematic computational investigation of the possibility to accelerate the rate-limiting thermal isomerizations of the rotary cycles of synthetic light-driven overcrowded alkene-based molecular motors through modulation of steric interactions. Choosing as reference system a second-generation motor known to accomplish rotary motion in the $\mathrm{MHz}$ regime and using density functional theory methods, we propose a three-step mechanism for the thermal isomerizations of this motor and show that variation of the steric bulkiness of the substituent at the stereocenter can reduce the (already small) free-energy barrier of the rate-determining step by a further $15-17 \mathrm{~kJ}$ $\mathrm{mol}^{-1}$. This finding holds promise for future motors of this kind to reach beyond the $\mathrm{MHz}$ regime. Furthermore, we demonstrate and explain why one particular step is kinetically favored by decreasing and another step is kinetically favored by increasing the steric bulkiness of this substituent, and identify a possible back reaction capable of impeding the rotary rate.
\end{abstract}




\section{Introduction}

Nature elegantly carries out a variety of complex biological tasks using systems that can be termed as molecular motors by their ability to perform work by absorbing external energy and converting the energy into directed (i.e., non-Brownian) mechanical motion such as rotation and translation. ${ }^{1}$ Of these systems, perhaps the most well-known is ATP synthase, ${ }^{2}$ which converts the energy stored in chemical bonds into directed rotary motion. Owing to their potential applications in nanotechnology, ${ }^{3-5}$ the design of synthetic molecular motors capable of mimicking Nature's precision and delicacy is a major research field ${ }^{6-13}$ that was pioneered by Kelly ${ }^{14}$ and Feringa ${ }^{15,16}$ and their coworkers in the late nineties. Motors that produce unidirectional rotary motion are commonly referred to as rotary molecular motors (or molecular rotors), and are characterized by their ability to control the direction of rotation, to rotate a full $360^{\circ}$, and to repeat the rotation for many cycles through consumption of energy.

Upon uptake of light energy, the motor developed by Feringa and co-workers produces unidirectional rotary motion around a carbon-carbon double bond in a sterically overcrowded alkene (Ia in Scheme 1 with $\mathrm{R}=\mathrm{Me}),{ }^{15,16}$ and has subsequently inspired a wealth of experimental research devoted to the design, synthesis and operation of improved motors of this kind. ${ }^{17-34}$ Several examples of such systems known as either first-generation or second-generation rotary molecular motors are shown in Scheme 1. All these motors, for which chirality is an essential feature and whose rotary cycles proceed through two photochemical steps and two rate-limiting thermal steps, have two identical or distinct halves attached to a central carbon-carbon double bond. In their functionalized forms, the lower-half "stator" is immobilized on a surface ${ }^{32,35-38}$ and the 
upper-half "rotator" rotates around the double-bond "axle". Due to steric overcrowding in the so-called fjord regions, the motor halves deviate from planarity to adopt helical structures, denoted $P$ or $M$ to indicate right-handed or left-handed helicity, respectively. ${ }^{15,16}$

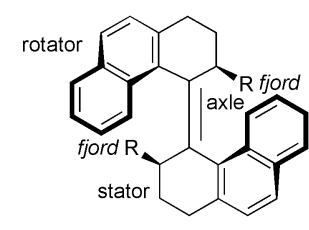

la

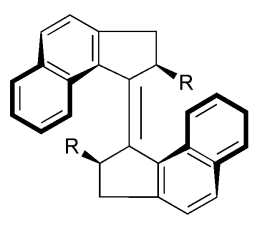

lb

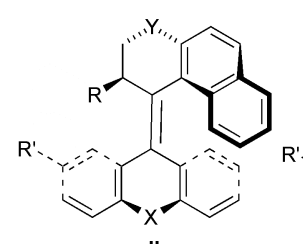

lla

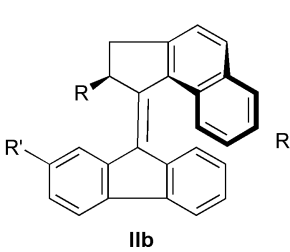

Ilb

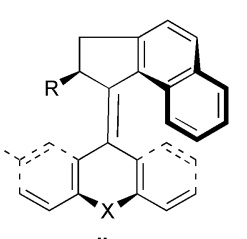

IIc

$\mathrm{X}, \mathrm{Y}=\mathrm{O}, \mathrm{S}, \mathrm{CH}_{2}$

Scheme 1 First-generation (Ia and Ib) and second-generation (IIa, IIb and IIc) lightdriven rotary molecular motors.

First-generation rotary molecular motors based on overcrowded biphenanthrylidenes (Ia in Scheme 1) $)^{15,16}$ and bicyclopenta[a]naphthalenylidenes (Ib in Scheme 1$)^{19}$ have the limitation that changing the substituents on the stereocenters (one stereocenter on both the stator and rotator) affects the thermal steps in an asymmetric fashion. ${ }^{24}$ Thus, if one of the thermal steps is accelerated by modifying the steric size of the substituents, then the other thermal step may be decelerated on the same grounds. ${ }^{24}$

In second-generation rotary molecular motors (e.g., IIa, IIb and IIc in Scheme 1), which contain a single stereocenter on the rotator, ${ }^{18,23,25,26,28}$ this limitation is circumvented by employing a nearly symmetric stator, whereby the two thermal steps are similarly affected by the stereogenic substituent. ${ }^{24}$ The type IIa motors typically employ 
a xanthene $(\mathrm{X}=\mathrm{O})$, thioxanthene $(\mathrm{X}=\mathrm{S})$ or anthracene-based $\left(\mathrm{X}=\mathrm{CH}_{2}\right)$ stator combined with a naphthopyran $(\mathrm{Y}=\mathrm{O})$, naphthothiopyran $(\mathrm{Y}=\mathrm{S})$ or phenanthrylidenebased $\left(\mathrm{Y}=\mathrm{CH}_{2}\right)$ rotator. $^{18,26}$

Each $360^{\circ}$ rotation achieved by a second-generation motor involves two photochemical and two thermal steps, which together make up the rotary cycle shown in Scheme 2 for the case of a type IIa motor with a methyl substituent on the rotator stereocenter and a methoxy substituent on the stator. ${ }^{18,26}$ Labelling isomers with the methyl substituent in a favorable pseudo-axial orientation as "stable" and isomers with the methyl substituent in a strained (because of steric overcrowding) pseudo-equatorial orientation as "unstable", the rotary cycle can be described as follows.
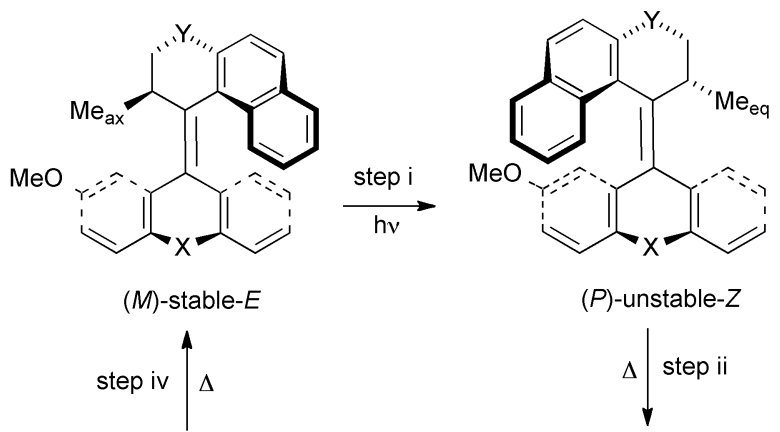

$$
(P) \text {-unstable- } Z
$$

$\Delta \downarrow$ step ii

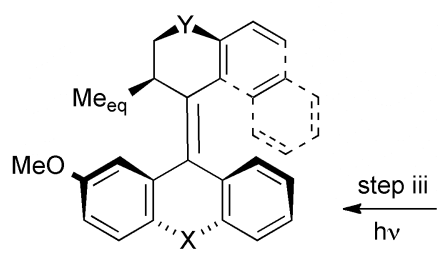

$(P)$-unstable- $E$

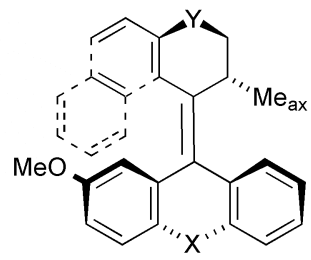

$(M)$-stable-Z

Scheme 2 Rotary cycle of a second-generation type IIa molecular motor with a methyl substituent on the rotator stereocenter and a methoxy substituent on the stator.

In the first step, irradiation of the $(M)$-stable- $E$ isomer with UV light triggers an $E$ $\rightarrow Z$ photoisomerization around the central carbon-carbon double bond to produce the $(P)$-unstable- $Z$ isomer. This reaction occurs concomitantly with a $M \rightarrow P$ inversion of the 
helicity of the rotator, and a change in orientation of the methyl substituent from favorable pseudo-axial in $(M)$-stable- $E$ to strained pseudo-equatorial in $(P)$-unstable- $Z$.

In $(P)$-unstable- $Z$, further isomerization continuing in the same direction as the initial $E \rightarrow Z$ isomerization is prevented by steric hindrance between the stator and rotator. However, this hindrance can be overcome in a thermally activated and spontaneous $P \rightarrow M$ helix inversion process, in which the methyl regains its preferred pseudo-axial orientation. This process constitutes the second step of the rotary cycle, produces the $(M)$-stable- $Z$ isomer, and completes the first $180^{\circ}$ of the rotation.

In the third step, irradiation of $(M)$-stable- $Z$ with $\mathrm{UV}$ light triggers a $Z \rightarrow E$ photoisomerization that generates the $(P)$-unstable- $E$ isomer. In analogy with the first step, this reaction also changes the helicity of the rotator from $M$ to $P$, and forces the methyl to adopt a strained pseudo-equatorial orientation in $(P)$-unstable- $E$. Because of the preceding thermal step, this photoisomerization can only proceed in the same direction as the $E \rightarrow Z$ photoisomerization during the first step. Accordingly, the two photoisomerizations occur in a unidirectional fashion and produce rotary motion.

In the fourth and final step of the rotary cycle, which is analogous to the second step, $(P)$-unstable- $E$ is converted to the starting $(M)$-stable- $E$ isomer through a spontaneous thermal $P \rightarrow M$ helix inversion, whereby the preferred pseudo-axial orientation of the methyl substituent is restored. This step completes the full $360^{\circ}$ rotation and allows for a new cycle to begin.

As noted above, the rotary motion of overcrowded alkene-based motors relies on steric interactions between the stator and rotator. In analogy with the mechanism recently found to be governing the unidirectional rotary motion naturally achieved by Anabaena 
sensory rhodopsin (a photosensory protein found in a cyanobacterium), ${ }^{39}$ these interactions render the thermal helix inversion steps exergonic, and help prevent back rotations that would otherwise impede the overall rotary motion. ${ }^{16,24}$ As the photochemical steps of these motors are known to be extraordinarily fast, comprising torsional motion along the $Z / E$ isomerization coordinates on a $\sim 0.1-2$ ps timescale and excited-state decay on a $\sim 1-10$ ps timescale, ${ }^{40,41}$ it is clear that it is the thermal helix inversions that limit the frequencies with which these systems are able to rotate.

A key aspect of fulfilling the potential of synthetic rotary molecular motors for future applications in, e.g., molecular transport ${ }^{42}$ and as tools for rotating objects much larger than themselves, ${ }^{43}$ is reaching high rotational frequencies under ambient conditions. ${ }^{24,44}$ A major experimental effort has therefore been invested in accelerating the rate-limiting thermal steps of overcrowded alkene-based rotary molecular motors, ${ }^{18,19,21,23-25,27,28,33}$ exploring the influence of conformational, steric and electronic factors. From such studies, it has been found that one way of lowering the thermal freeenergy barriers of type IIa motors is to contract the sizes of the rotator and stator by employing a cyclopenta[a]naphthalenylidene rotator and a fluorene stator, as done in type IIb motors. ${ }^{23,28}$ Furthermore, for type IIb motors, using a bulkier stereogenic substituent than methyl has also been found to lower the thermal barriers. ${ }^{23}$ One other variant of a second-generation motor is the type IIc motor shown in Scheme 3, hereafter referred to as motor $\mathbf{1}$, in which the cyclopenta[a]naphthalenylidene rotator adapted in type IIb motors is combined with the thioxanthene stator commonly used in type IIa motors. Due to its small thermal energy barriers, this motor has been found capable of achieving rotational frequencies in $\mathrm{MHz}$ regime. ${ }^{25}$ 


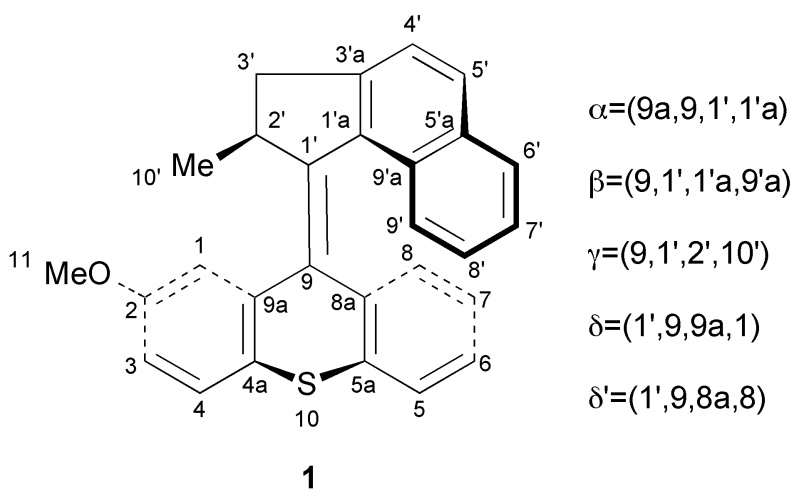

Scheme 3 Atom numbering and definition of dihedral angles in the $(S, E)$-2-methoxy-9(2-methyl-2,3-dihydro-1H-cyclopenta[a]-napthalen-1-ylidene)-9H-thioxanthene molecular motor 1.

Complementing these experimental efforts are a number of computational studies that have offered valuable mechanistic insight into the photochemical steps of overcrowded alkene-based rotary molecular motors, ${ }^{45-50}$ and also identified other molecules as possible light-driven rotary motors. ${ }^{51-53}$ As to the photochemical steps, such studies have found that the $E \rightarrow Z$ and $Z \rightarrow E$ isomerizations occur in the lowest excited singlet state $\left(\mathrm{S}_{1}\right)$, which can be characterized as a HOMO $\rightarrow$ LUMO $\pi \pi^{*}$ state, $^{46-48}$ and proceed in an almost barrierless fashion. ${ }^{47,48}$ The latter result is consistent with the ultrafast excited-state dynamics that, as mentioned above, have been observed experimentally for these motors. ${ }^{40,41}$ Computational studies have also found that the excited-state decay that precedes the formation of the isomerized $(P)$-unstable- $Z$ and $(P)$ unstable- $E$ photoproduct species occurs non-radiatively through conical intersections with the ground state. ${ }^{47,48}$

Although the value of computational studies in this field of research has thus been amply demonstrated, it is surprising that no such studies have been devoted to systematically investigate ways to lower the critical thermal free-energy barriers of 
overcrowded alkene-based rotary motors. Using density functional theory (DFT) methods, the present study is an attempt to help filling this important gap. As such, our work is related to previous quantum chemical studies by other authors exploring the mechanisms of the thermal helix inversion steps of both first-generation type Ia motors using semiemperical methods $\mathrm{s}^{45,54}$ and second-generation type IIa motors using DFT ${ }^{26,55}$ and Monte Carlo-like methods. ${ }^{56}$ Furthermore, it is also related to our own recent DFTbased study ${ }^{57}$ in which we explored the mechanistic details of the full rotary cycle of a methyl-substituted first-generation type Ia motor. Specifically, the present work systematically investigates the influence of fjord-region steric interactions on the thermal helix inversion steps of motor $\mathbf{1}$ and several stator and rotator-substituted variants thereof, with the aim to unveil some guiding principles for the design of faster (than motor 1) rotating motors by control of steric effects.

Starting with motor 1 and using a variety of density functionals, we first propose a reaction mechanism for the thermal steps of this motor that is consistent with available kinetic data. $^{25}$ Then, we apply our computational methodology to eight new potential light-driven rotary molecular motors (molecules $\mathbf{2}-\mathbf{9}$ in Scheme 4) derived by replacing the stator methoxy substituent and rotator methyl substituent of motor $\mathbf{1}$ with groups of varying steric bulkiness, that are commonly employed in overcrowded alkene-based motors. $^{20,23,28}$ Through the modeling of the thermal processes of these motors, which are found to proceed in three separate steps, we demonstrate and explain why one step is kinetically favored by decreasing and another step is kinetically favored by increasing the steric bulkiness of the rotator substituent. Additionally, we identify three substitutions of the rotator methyl group of motor $\mathbf{1}$ that, according to the calculations, would lower the 
free-energy barrier of the rate-determining thermal step by $15-17 \mathrm{~kJ} \mathrm{~mol}^{-1}$. This prediction suggests a route for bringing the rotational frequencies of overcrowded alkenebased motors well beyond the $\mathrm{MHz}$ regime. ${ }^{25}$

Finally, as a minor yet important complement to the modeling of the thermal steps, we also present data from preliminary modeling of the photochemical steps of molecules 2-9 (as well as of motor 1) confirming that these systems are indeed rotary motors whose $E \rightarrow Z$ and $Z \rightarrow E$ photoisomerizations occur in a unidirectional fashion.

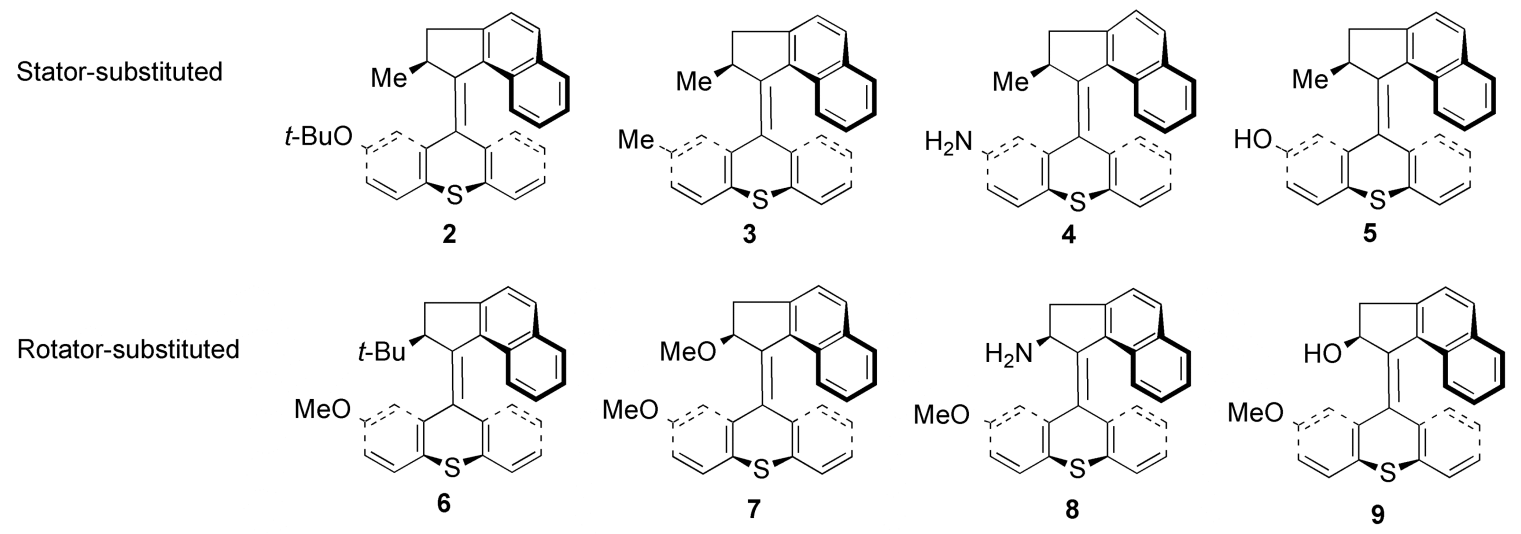

Scheme 4 Potential light-driven rotary molecular motors considered in this work.

\section{Computational methods}

In our previous study, ${ }^{57}$ the range-separated and dispersion-corrected ${ }^{58,59} \omega \mathrm{B} 97 \mathrm{X}-\mathrm{D}^{60}$ hybrid density functional showed good overall performance for the full rotary cycle of the original type Ia Feringa motor. Therefore, it was decided to use this method also in the present work. However, for comparative purposes, the thermal steps of motor 1 were also explored using a set of complementary hybrid functionals. This set included CAM- 
${\mathrm{B} 3 \mathrm{LYP}^{61} \text { (another range-separated hybrid), B3LYP, }{ }^{62,63} \mathrm{PBE0}^{64,65} \text { and M06-2X }}^{66,67}$ (global hybrids).

The thermal steps of motor $\mathbf{1}$ were explored in the following way. First, stationary points on the ground-state $\left(\mathrm{S}_{0}\right)$ potential energy surface (PES) corresponding to the $(M)$ stable- $E$ and $(M)$-stable- $Z$ light-absorbing isomers and the $(P)$-unstable- $Z$ and $(P)$ unstable- $E$ photoproduct isomers were located by performing geometry optimizations with all of the aforementioned functionals in combination with the double- $\xi \mathrm{SVP}^{68}$ basis set, as well as with (for $\omega$ B97X-D only) the larger $6-31++\mathrm{G}(\mathrm{d}, \mathrm{p})^{69-71}$ and cc-pVTZ ${ }^{72}$ basis sets. Of these, $6-31++G(d, p)$ contains diffuse functions and cc-pVTZ is a correlation-consistent triple- $\xi$ basis set. To describe the dichloromethane solvent used in the experimental reference study, ${ }^{25}$ the calculations were carried out employing the SMD continuum solvation model. ${ }^{73}$ For the resulting geometries, frequency calculations were performed at the corresponding levels of theory to ensure that these structures are potential-energy minima, and to derive Gibbs free energies at room temperature.

Having located the $(M)$-stable- $E$ and $(M)$-stable- $Z$ light-absorbing isomers and the $(P)$-unstable- $Z$ and $(P)$-unstable- $E$ photoproduct isomers, the mechanism of the thermal $(P)$-unstable- $Z \rightarrow(M)$-stable- $Z$ and $(P)$-unstable- $E \rightarrow(M)$-stable- $E$ reactions were then investigated by locating all the relevant transition structures (TSs). Besides optimization of transition structures, this investigation involved frequency and intrinsic reaction coordinate (IRC) ${ }^{74}$ calculations to obtain Gibbs free energies and to verify that the transition structures found connect the associated reactant and product species. To solidify the conclusions as best as possible, these calculations were performed (using an 
SMD description of the dichloromethane solvent) with all of the density functionals mentioned earlier.

The calculations exploring the rotary cycles of motors $\mathbf{2}-\mathbf{9}$, finally, were done in the same way as the calculations on motor $\mathbf{1}$ just described, but exclusively at the $\omega \mathrm{B} 97 \mathrm{X}-\mathrm{D} / \mathrm{SVP}$ level of theory. As will be further discussed below, this choice of level can be justified by the observation that it affords good agreement with experimental data

on the thermal kinetics of motor $\mathbf{1} \cdot{ }^{25}$ Also, through the inclusion of empirical atom-atom dispersion corrections, ${ }^{58,59} \omega \mathrm{B} 97 \mathrm{X}-\mathrm{D}$ is well suited to describe intramolecular interactions between the stator and rotator.

Except where otherwise noted, all calculations were performed with the Gaussian 09 suite of programs. ${ }^{75}$

\section{Results and discussion}

\section{1 syn- and anti-folded isomers of motor 1}

Before discussing mechanistic details of the rotary cycle of motor $\mathbf{1}$, it should be noted that both the light-absorbing isomers and the photoproduct isomers were found to have two possible conformations of the stator and rotator relative to the plane containing the C9- ${ }^{-} 1$ ' bond and the stereocenter (henceforth referred to as the olefinic plane). This is illustrated in Fig. 1, and has also been observed for other second-generation motors ${ }^{26,55}$ and structurally related bistricyclic aromatic enes like dithioxanthylene and dixanthylene. ${ }^{76}$ In the $s y n$-folded conformation, the stator and rotator point toward the same side of the olefinic plane, whereas they point toward opposite sides in the antifolded conformation. As a result, the latter conformation exhibits less steric overcrowding in the fjord regions than the former, and lies lower in energy. As can be 
seen from Table S1 of the Electronic Supplementary Information (ESI), this holds true for each of the four species at all levels of theory employed.

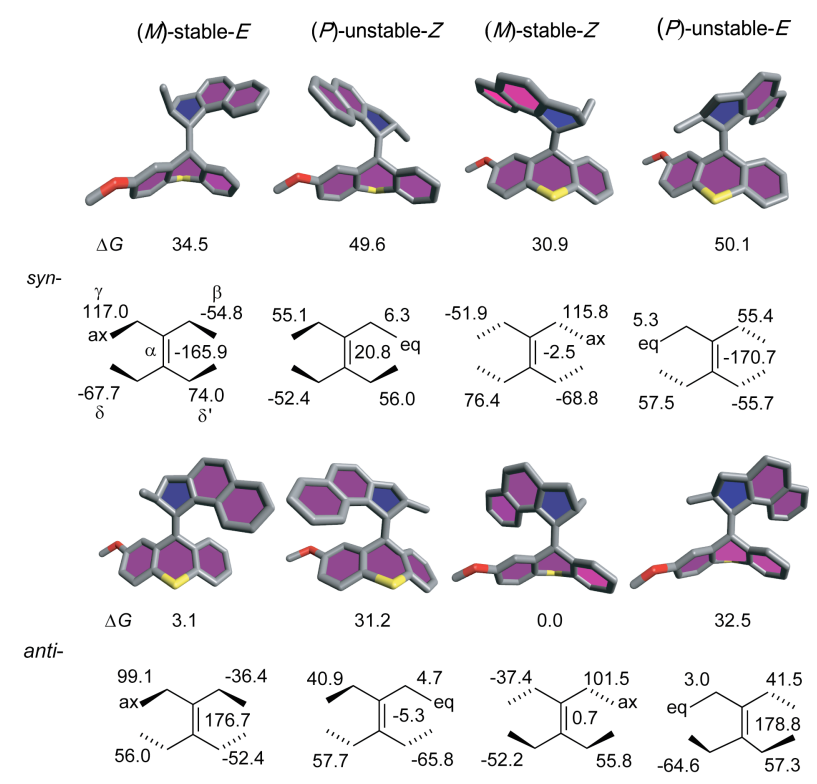

Fig. 1 Structures of syn- and anti-folded isomers of motor 1 and their $\alpha, \beta, \gamma, \delta$ and $\delta^{\prime}$ dihedral angles (in degrees) and relative free energies $\left(\Delta G\right.$, in $\left.\mathrm{kJ} \mathrm{mol}^{-1}\right)$.

From Table S1 (all levels of theory) and Fig. 1 ( $\omega$ B97X-D/SVP), it can also be seen that the energetic preference of the anti-folded conformation is more pronounced in the $(M)$-stable- $E$ and $(M)$-stable- $Z$ light-absorbing isomers, in which the stereogenic methyl substituent adopts a favorable pseudo-axial orientation, than in the $(P)$-unstable- $Z$ and $(P)$-unstable- $E$ photoproduct isomers that have the methyl in a strained pseudoequatorial orientation. Naturally, the two most stable (by some $30 \mathrm{~kJ} \mathrm{~mol}^{-1}$ ) of the eight species are the ones in which a favorable pseudo-axial orientation of the methyl is combined with an anti-folded conformation of the stator and rotator. These are the lightabsorbing anti-(M)-stable- $E$ and anti-( $M)$-stable- $Z$ isomers. 
On a technical note, while $\omega \mathrm{B} 97 \mathrm{X}-\mathrm{D} / \mathrm{SVP}$ predicts anti- $(M)$-stable- $Z$ to be the more stable of these two isomers, all other levels of theory in Table S1 favor anti-(M)stable- $E$. However, since the free-energy difference between the two species is very small $\left(1-3 \mathrm{~kJ} \mathrm{~mol}^{-1}\right)$ at all levels, this discrepancy is not, we believe, a cause for concern.

Having found that the parent, light-absorbing $(M)$-stable- $E$ and $(M)$-stable- $Z$ isomers are anti-folded, it is of interest to assess whether this holds true also for the $(P)$ unstable- $Z$ and $(P)$-unstable- $E$ photoproducts. Clearly, this question is best addressed by modeling the photochemical steps that produce these species. As noted in the Introduction, such modeling is also important for verifying that the photochemical steps actually sustain rotary motion. Here, we will present results suggesting that the photoproducts are rather $s y n$-folded, thus indicating that the stator-rotator folding changes from anti to syn during the photochemical steps of motor $\mathbf{1}$. Such a scenario would be consistent with ${ }^{1} \mathrm{H}-\mathrm{NMR}$ data on the rotary cycle of a second-generation motor with a dibenzocyclohepten-5-ylidene stator, ${ }^{26}$ but is not a common feature for second-generation motors. ${ }^{26}$

Specifically, the first piece of evidence that the stator-rotator folding changes during the photochemical steps of motor $\mathbf{1}$ is obtained by modeling the geometric relaxation from the vertically excited Franck-Condon (FC) point in the $S_{1}$ state populated by light absorption of the anti-(M)-stable- $E$ and anti-(M)-stable- $Z$ species. This relaxation produces excited-state minima henceforth denoted anti-(M)-stable- $E^{*}$ and anti-(M)stable- $Z^{*}$, and constitutes the initial stages of the $E \rightarrow Z$ and $Z \rightarrow E$ photoisomerizations through which the $(P)$-unstable- $Z$ and $(P)$-unstable- $E$ photoproducts are formed. Performing excited-state geometry optimizations using time-dependent DFT (TD- 
DFT) $)^{77-85}$ within the Tamm-Dancoff approximation (TDA) $)^{86-89}$ and also using the $a b$ initio approximate coupled-cluster singles and doubles $(\mathrm{CC} 2)$ method $^{90}$ as implemented in the Turbomole 6.3 suite of programs, ${ }^{91,92}$ key results from these calculations are presented in Table 1.

Table 1 Geometric changes (in $\AA$ and degrees) during the FC relaxation of the anti-(M)-stable- $E$ and anti-( $M)$-stable- $Z$ isomers of motor 1 and associated relaxation energies $\left(\Delta E_{\mathrm{R}} \text {, in } \mathrm{eV}\right)^{a}$

\begin{tabular}{|c|c|c|c|c|c|c|c|c|}
\hline \multirow[b]{2}{*}{ Level of theory } & \multicolumn{4}{|c|}{ anti-(M)-stable- $E$} & \multicolumn{4}{|c|}{ anti- $(M)$-stable- $Z$} \\
\hline & C9-C1' & $\alpha$ & $\delta$ & $\Delta E_{\mathrm{R}}$ & C9-C1' & $\alpha$ & $\delta$ & $\Delta E_{\mathrm{R}}$ \\
\hline$\omega \mathrm{B} 97 \mathrm{X}-\mathrm{D} / \mathrm{I}^{b}$ & $1.353 \rightarrow 1.432$ & $176.8 \rightarrow 146.5$ & $55.8 \rightarrow 29.0$ & 0.74 & $1.353 \rightarrow 1.433$ & $0.9 \rightarrow-27.4$ & $-52.3 \rightarrow-27.7$ & 0.69 \\
\hline$\omega \mathrm{B} 97 \mathrm{X}-\mathrm{D} / \mathrm{II}^{c}$ & $1.351 \rightarrow 1.432$ & $178.2 \rightarrow 145.3$ & $56.7 \rightarrow 27.2$ & 0.75 & $1.350 \rightarrow 1.434$ & $2.3 \rightarrow-35.9$ & $-53.7 \rightarrow-25.3$ & 0.74 \\
\hline$\omega \mathrm{B} 97 \mathrm{X}-\mathrm{D} / \mathrm{III}^{d}$ & $1.343 \rightarrow 1.427$ & $177.7 \rightarrow 145.1$ & $56.3 \rightarrow 26.4$ & 0.76 & $1.343 \rightarrow 1.428$ & $2.0 \rightarrow-34.8$ & $-53.6 \rightarrow-25.3$ & 0.75 \\
\hline $\mathrm{B} 3 \mathrm{LYP} / \mathrm{I}^{b}$ & $1.365 \rightarrow 1.422$ & $177.3 \rightarrow 153.2$ & $54.8 \rightarrow 32.0$ & 0.45 & $1.364 \rightarrow 1.420$ & $-1.2 \rightarrow-27.3$ & $-52.4 \rightarrow-33.7$ & 0.41 \\
\hline $\mathrm{PBE} 0 / \mathrm{I}^{b}$ & $1.360 \rightarrow 1.421$ & $177.5 \rightarrow 151.7$ & $54.7 \rightarrow 29.2$ & 0.52 & $1.360 \rightarrow 1.419$ & $-0.8 \rightarrow-28.2$ & $-52.1 \rightarrow-30.9$ & 0.47 \\
\hline $\mathrm{M} 06-2 \mathrm{X} / \mathrm{I}^{b}$ & $1.354 \rightarrow 1.430$ & $176.7 \rightarrow 148.7$ & $55.2 \rightarrow 28.8$ & 0.73 & $1.354 \rightarrow 1.431$ & $-0.3 \rightarrow-26.7$ & $-51.5 \rightarrow-27.9$ & 0.67 \\
\hline CAM-B3LYP/I ${ }^{b}$ & $1.353 \rightarrow 1.433$ & $177.7 \rightarrow 145.3$ & $55.7 \rightarrow 24.9$ & 0.76 & $1.353 \rightarrow 1.434$ & $0.0 \rightarrow-38.4$ & $-53.1 \rightarrow-24.6$ & 0.75 \\
\hline $\mathrm{CC} 2 / \mathrm{I}^{b}$ & $1.370 \rightarrow 1.446$ & $175.2 \rightarrow 145.3$ & $54.6 \rightarrow 27.7$ & 0.74 & $1.370 \rightarrow 1.446$ & $-0.1 \rightarrow-26.4$ & $-50.9 \rightarrow-27.6$ & 0.67 \\
\hline
\end{tabular}

${ }^{a}$ Geometry optimizations performed in the gas phase and singlepoint calculations performed using an SMD description of the dichloromethane solvent. ${ }^{b}$ Calculations carried out with the SVP basis set. ${ }^{c}$ Calculations carried out with the $6-31++\mathrm{G}(\mathrm{d}, \mathrm{p})$ basis set. ${ }^{d}$ Calculations carried out with the cc-pVTZ basis set.

From Table 1, it is found that the stator-rotator folding relative to the olefinic plane (as described in terms of the $\delta$ dihedral angle) is changed by a sizable $20-30^{\circ}$ during the FC relaxation of the anti-(M)-stable- $E$ and anti-(M)-stable- $Z$ species, although the resulting excited-state minima remain anti-folded. Complementing these results are further calculations presented in Fig. S1 of the ESI, which indicate that the stator-rotator folding is fully changed from anti to syn during the subsequent transformation of the anti$(M)$-stable- $E^{*}$ and anti-( $\left.M\right)$-stable- $Z^{*}$ minima into the $(P)$-unstable- $Z$ and $(P)$-unstable- $E$ photoproducts, as a consequence of a ring flip of the stator relative to the olefinic plane.

Table 1 also shows that the FC relaxation involves both a pronounced lengthening of the $\mathrm{C} 9-\mathrm{C} 1$ ' bond, which facilitates photoisomerization, and torsional motion along the $\alpha$ photoisomerization coordinate. For both isomers, the bond lengthening amounts to 
$0.06-0.10 \AA$ and the torsional motion to $26^{-}-38^{\circ}$, depending on which level of theory is used. On the whole, the variation in these estimates is more due to the choice of quantum chemical method, than to the choice of basis set (SVP, 6-31++G(d,p), or cc-pVTZ). For example, the basis-set effect on the bond lengthening is smaller than $0.01 \AA$. Although the torsional motion is appreciable, the anti-(M)-stable- $E^{*}$ and anti-(M)-stable- $Z^{*}$ minima are well separated from the highly twisted molecular geometries closer to $\alpha= \pm 90^{\circ}$ whose accurate description would require more advanced quantum chemical methods than TD-DFT and CC2 (i.e., multi-reference methods that explicitly include neardegeneracy effects ${ }^{93}$ ). Hence, the failure of TD-DFT and CC2 to properly account for near-degeneracy effects should not, we believe, compromise the modeling of the FC relaxation. This notion is supported by previous computational studies of double-bond photoisomerizations in smaller organic molecules showing good agreement between excited-state PESs obtained with TD-DFT and multi-reference methods. ${ }^{94,95}$

Finally, as to verifying that the photochemical steps sustain rotary motion, this can indeed be inferred from the observation in Table 1 that the changes in the $\alpha$ dihedral angle during the FC relaxation have the same sign (negative) for anti- $(M)$-stable- $E$ and anti-(M)-stable- $Z$. In other words, the $E \rightarrow Z$ and $Z \rightarrow E$ photoisomerizations occur in a unidirectional fashion.

\subsection{The thermal steps of motor 1}

In the syn-folded photoproducts, henceforth denoted syn- $(P)$-unstable- $Z$ and $s y n-(P)-$ unstable- $E$, the stereogenic methyl substituent on the rotator is trapped in a strained pseudo-equatorial orientation. As the helicity of the rotator is changed from $P$ to $M$ 
during the thermal syn-(P)-unstable- $Z \rightarrow$ anti-( $(M)$-stable- $Z$ and syn-(P)-unstable- $E \rightarrow$ anti-(M)-stable- $E$ isomerizations, depicted in Scheme 5, the methyl regains its preferred pseudo-axial orientation. Furthermore, the conformation of the stator and rotator relative to the olefinic plane changes from syn to anti. As a result, the thermal isomerizations occur spontaneously (i.e., with a lowering of the free energy). This introduces irreversibility into the rotary cycle and prevents the unidirectional rotary motion from being impeded by back rotations. ${ }^{16,24}$
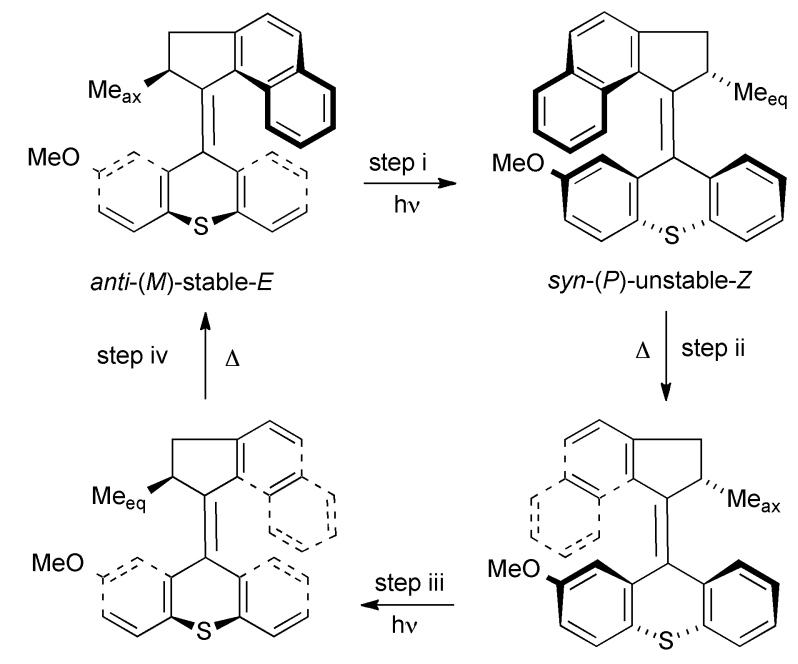

syn-(P)-unstable- $Z$

syn-(P)-unstable- $E$

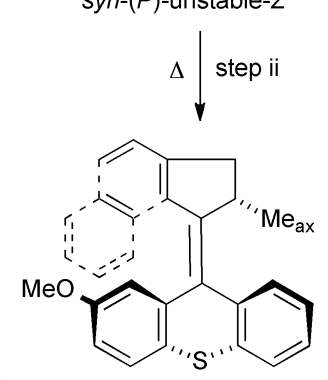

anti-(M)-stable- $Z$

Scheme 5 Overall rotary cycle of motor 1.

Given that the photochemical steps of overcrowded alkene-based motors are very fast, ${ }^{40,41}$ the key to attain higher rotational frequencies is to accelerate the rate-limiting thermal steps. For this purpose, a detailed understanding of the mechanism of these processes is crucial, but currently not available (stepwise mechanisms have been proposed for type IIa motors; ${ }^{26,55,56}$ however, for type IIc motor 1, mechanistic details are largely unknown in terms of both experimental and computational data). Here, we will propose a three-step mechanism for the thermal isomerizations of motor $\mathbf{1}$, based 
upon which we will subsequently suggest a number of chemical substitutions for surpassing the $\mathrm{MHz}$ rotational frequencies that this system can achieve. ${ }^{25}$ As we will see, the proposed mechanism involves only exergonic steps and has a rate-determining freeenergy barrier that agrees well with the experimental value of $35 \mathrm{~kJ} \mathrm{~mol}^{-1} .25$

The proposed three-step mechanism is presented in Fig. 2, which includes the relevant stationary points and their relative free energies as obtained at the $\omega \mathrm{B} 97 \mathrm{X}$ D/SVP level of theory. Associated key geometric parameters are given in Table S2 of the ESI and, for other levels of theory, also in Tables S3-S6. In Table S7, a comparison is made between the free-energy barriers of Fig. 2 and those calculated at other levels of theory. 

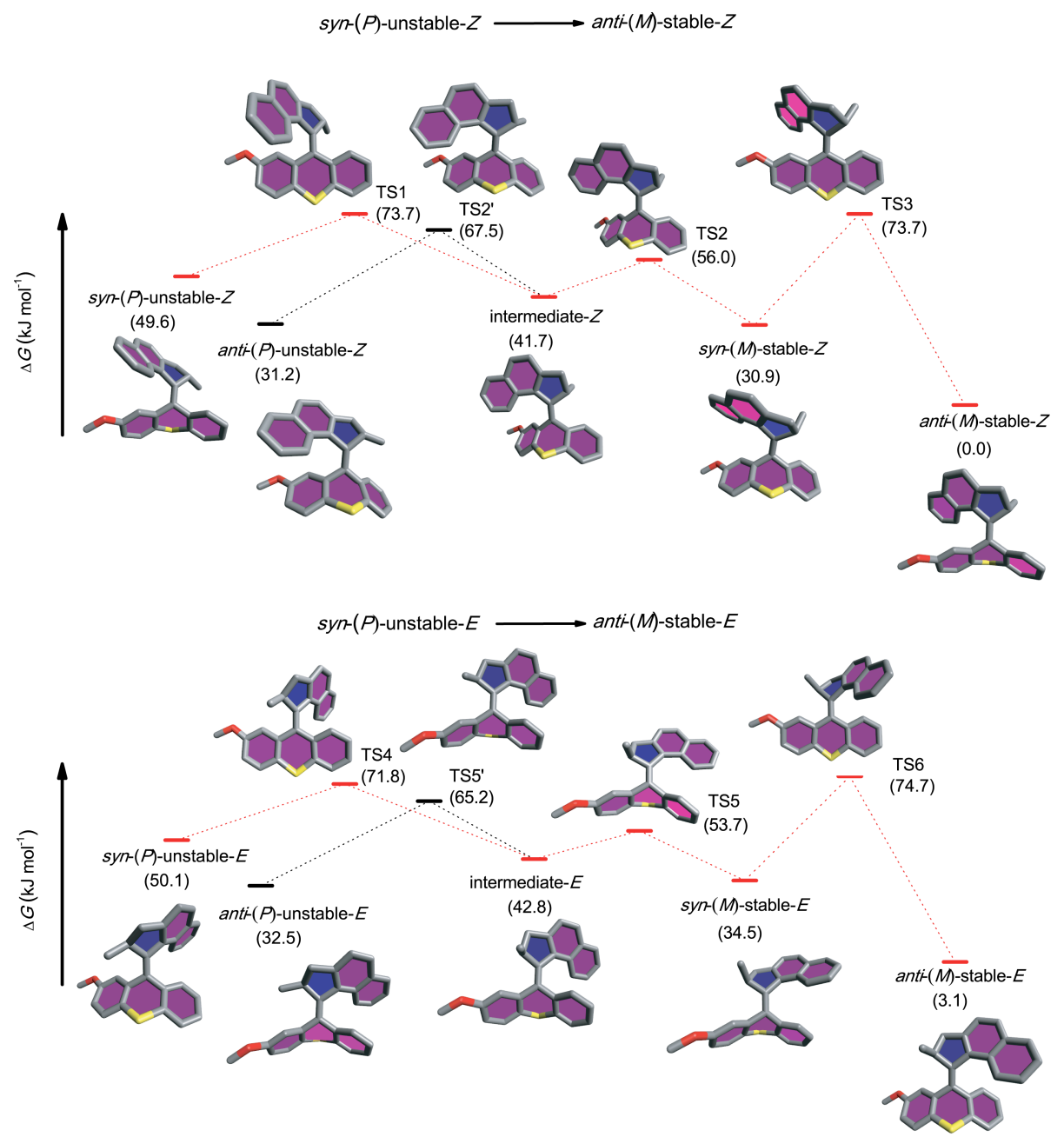

Fig. 2 Proposed mechanism for the thermal isomerizations of the syn- $(P)$-unstable- $Z$ and syn- $(P)$-unstable- $E$ isomers of motor 1 with relative free energies of stationary points given in parentheses.

Starting from syn- $(P)$-unstable- $Z$ in the "first" half of the rotary cycle, the rotator first loses its $P$ helicity through the formation of the intermediate- $Z$ species via TS1. This step is estimated to have a barrier of a facile $24 \mathrm{~kJ} \mathrm{~mol}^{-1}$ and an exergonicity of $8 \mathrm{~kJ} \mathrm{~mol}^{-}$ 1 , and is accompanied by a partial release of the conformational strain experienced by the pseudo-equatorial methyl substituent in syn-(P)-unstable- $Z$ and a ring flip of the stator relative to the olefinic plane. Somewhat more quantitatively (see Table S2) in terms of the dihedral angles defined in Scheme 3, this step involves changes in $\beta\left(55.1 \rightarrow 10.1^{\circ}\right), \gamma$ 
$\left(6.3 \rightarrow 72.7^{\circ}\right)$ and $\delta\left(-52.4 \rightarrow 47.6^{\circ}\right)$, which respectively reflect rotator helicity, methyl orientation and stator-rotator folding relative to the olefinic plane.

In the second step, the rotator attains $M$ helicity as intermediate- $Z$ is transformed into $\operatorname{syn}$ - $(M)$-stable- $Z$ via TS2 $\left(\beta: 10.1 \rightarrow-51.9^{\circ}\right)$. As this happens, the methyl fully releases its conformational strain and assumes its preferred pseudo-axial orientation ( $\gamma$ : $\left.72.7 \rightarrow 115.8^{\circ}\right)$. Also for this step do the calculations yield a small barrier $\left(14 \mathrm{~kJ} \mathrm{~mol}^{-1}\right)$ and a favorable reaction energy $\left(-11 \mathrm{~kJ} \mathrm{~mol}^{-1}\right)$.

Possibly competing with the second step, we have also identified a back reaction of intermediate- $Z$ that forms anti-(P)-unstable- $Z$ via TS2' and a barrier of $26 \mathrm{~kJ} \mathrm{~mol}^{-1}$. In this reaction, the rotator regains the $P$ helicity lost during the first step of the forward reaction $\left(\beta: 10.1 \rightarrow 40.9^{\circ}\right.$ ), and the methyl goes back to a pseudo-equatorial orientation $\left(\gamma: 72.7 \rightarrow 4.7^{\circ}\right)$. Contrary to the first step of the forward reaction, the back reaction occurs without a stator ring flip $\left(\delta: 47.6 \rightarrow 57.8^{\circ}\right)$. Such a two-step equilibration between syn-( $(P)$-unstable- $Z$ and anti-( $(P)$-unstable- $Z$ might explain the experimental non-detection of $s y n$-folded isomers of second-generation type IIa motors, ${ }^{26}$ and also has been observed for structurally related dithioxanthylenes. ${ }^{96}$ Although the barrier of the back reaction is quite different $\left(26 \mathrm{~kJ} \mathrm{~mol}^{-1}\right)$ from the barrier of the forward reaction of intermediate- $Z$ that forms $\operatorname{syn}$ - $(M)$-stable- $Z$ via TS2 $\left(14 \mathrm{~kJ} \mathrm{~mol}^{-1}\right)$, it is difficult to assess to what extent the back reaction has a negative impact on the overall rotary rate, without taking into consideration also the energetics of the other steps of the rotary cycle. We will briefly return to this point below.

In the third and final step of the first half cycle, the folding of the stator and rotator relative to the olefinic plane is changed from syn to anti through a stator ring flip 
$\left(\delta: 76.4 \rightarrow-52.2^{\circ}\right)$. This transforms, via TS3, syn-(M)-stable- $Z$ into the light-absorbing anti-(M)-stable- $Z$ isomer from which the second half cycle begins. While this step has the most favorable reaction energy $\left(-31 \mathrm{~kJ} \mathrm{~mol}^{-1}\right)$ of the first half cycle, its barrier is the largest $\left(43 \mathrm{~kJ} \mathrm{~mol}^{-1}\right)$, thus rendering it the rate-determining step. Notably, this value is in good agreement with the experimental estimate that the rate-determining free-energy barrier in the first half cycle of motor $\mathbf{1}$ amounts to $35 \mathrm{~kJ} \mathrm{~mol}^{-1}$ in dichloromethane. ${ }^{25}$

The reason why the TS3 barrier is larger than the TS1 and TS2 barriers is, we believe, related to the combination of strong steric repulsion in TS3 from the close contact between the stator and rotator methyl substituent during the $s y n \rightarrow$ anti transition in stator-rotator folding, and minimal steric repulsion in the associated reactant species (i.e., in syn-(M)-stable-Z). This scenario will be further assessed in the next section.

Overall, the thermal isomerization of syn- $(P)$-unstable- $Z$ into anti- $(M)$-stable- $Z$ is driven by a net free-energy lowering of a substantial $50 \mathrm{~kJ} \mathrm{~mol}^{-1}$. Similarly, through its role as a kinetic sink, anti-( $M)$-stable- $Z$ also provides a $42 \mathrm{~kJ} \mathrm{~mol}^{-1}$ driving "force" for the two-step forward reaction of intermediate- $Z$. This, we believe, is likely to reduce the potential negative impact on the overall rotary rate from the aforementioned back reaction of intermediate- $Z$. At the same time, the barrier of the back reaction is smaller $\left(26 \mathrm{~kJ} \mathrm{~mol}^{-1}\right)$ than the largest barrier of the two-step forward reaction of intermediate- $Z$ $\left(43 \mathrm{~kJ} \mathrm{~mol}^{-1}\right)$. In this light, a conclusive assessment of the impact of the back reaction would require more quantitative kinetic modeling.

Turning to the "second" half of the rotary cycle and the thermal isomerization of syn-(P)-unstable- $E$ into anti-( $(M)$-stable- $E$, the associated mechanism and free-energy profile through TS4, TS5 and TS6 are fully analogous to those of the first half cycle just 
described. Thus, the rate-determining step is the final transformation of syn-(M)-stable- $E$ into anti-(M)-stable- $E$ via TS6 and a stator ring flip relative to the olefinic plane ( $\delta$ : $-67.7 \rightarrow 56.0^{\circ}$ ). Again, the $40 \mathrm{~kJ} \mathrm{~mol}^{-1}$ computational estimate of this barrier is in good agreement with the corresponding experimental value of $34 \mathrm{~kJ} \mathrm{~mol}^{-1} \cdot{ }^{25}$ Furthermore, also in the second half cycle is an undesirable back reaction of intermediate- $E$ identified, whose barrier via TS5' $\left(22 \mathrm{~kJ} \mathrm{~mol}^{-1}\right)$ is smaller than the TS6 barrier $\left(40 \mathrm{~kJ} \mathrm{~mol}^{-1}\right)$. The similarities between the two half cycles are reflected by the observation that each of the three steps in the two cycles is estimated to have a barrier and a reaction energy that agree to within $3 \mathrm{~kJ} \mathrm{~mol}^{-1}$ with the estimated barrier and reaction energy for the corresponding step in the other half cycle. This is a consequence of the stator being nearly symmetric. From Table S7, it can also be seen that none of the calculated freeenergy barriers of Fig. 2 is particularly sensitive to the level of theory employed ( $\omega$ B97X$\mathrm{D} / \mathrm{SVP}$ ). In fact, considering all barriers the maximum variation relative to other levels of theory lies within $14 \mathrm{~kJ} \mathrm{~mol}^{-1}$.

Finally, it should be pointed out that although the proposed three-step mechanism for the thermal isomerizations appears consistent with experimental kinetic data, ${ }^{25}$ there is one possible effect that could impact the actual reaction pathways, that we have not accounted for. Namely, it is possible that the starting syn-(P)-unstable- $Z$ and syn- $(P)$ unstable- $E$ photoproducts - following excited-state decay - reside in vibrationally hot states. If so, the time scale of vibrational cooling becomes an important factor. Indeed, if the cooling is slow compared to the thermal isomerizations of the photoproducts, these processes could effectively take place in fewer than three steps. Such effects in organic reactions in solution have been demonstrated ${ }^{97,98}$ through the modeling of vibrational 
cooling by means of the isolated-binary-collision model ${ }^{97,99}$ implemented in the MESMER code. ${ }^{100}$

\subsection{Accelerating the thermal steps through steric control}

Having proposed a three-step mechanism for the thermal isomerizations of motor $\mathbf{1}$, we now turn to exploring how the isomerizations may be accelerated by modulating the fjord-region steric interactions through replacement of the stator methoxy and rotator methyl substituents of motor 1 with groups of different steric bulkiness. In terms of the well-known parameters developed by Taft, ${ }^{101,102}$ the groups considered include - in order of increasing steric bulkiness - hydroxyl $(-0.55)$, methoxy $(-0.55)$, amino $(-0.61)$, methyl (-1.24) and tert-butyl (-2.78) groups, ${ }^{103}$ and were applied to both the stator (motors 2-5) and rotator (motors 6-9). The corresponding calculations were principally carried out at the $\omega \mathrm{B} 97 \mathrm{X}-\mathrm{D} / \mathrm{SVP}$ level of theory, which performed well for motor $\mathbf{1}$. For each of motors $\mathbf{2 - 9}$, the thermal isomerizations were found to occur by the same exact three-step mechanism and via the same types of transition structures (TS1-TS3 in the first rotary half cycle; TS4-TS6 in the second) as the thermal isomerizations of motor 1. Table S8 of the ESI summarizes the resulting free-energy barriers for motors 2-9. Fig. 3, in turn, shows the magnitudes of these barriers relative to the corresponding barriers for motor $\mathbf{1}$, with negative (positive) $\Delta \Delta G^{\ddagger}$ values implying that the barriers in question are smaller (larger) than those of motor $\mathbf{1}$. 


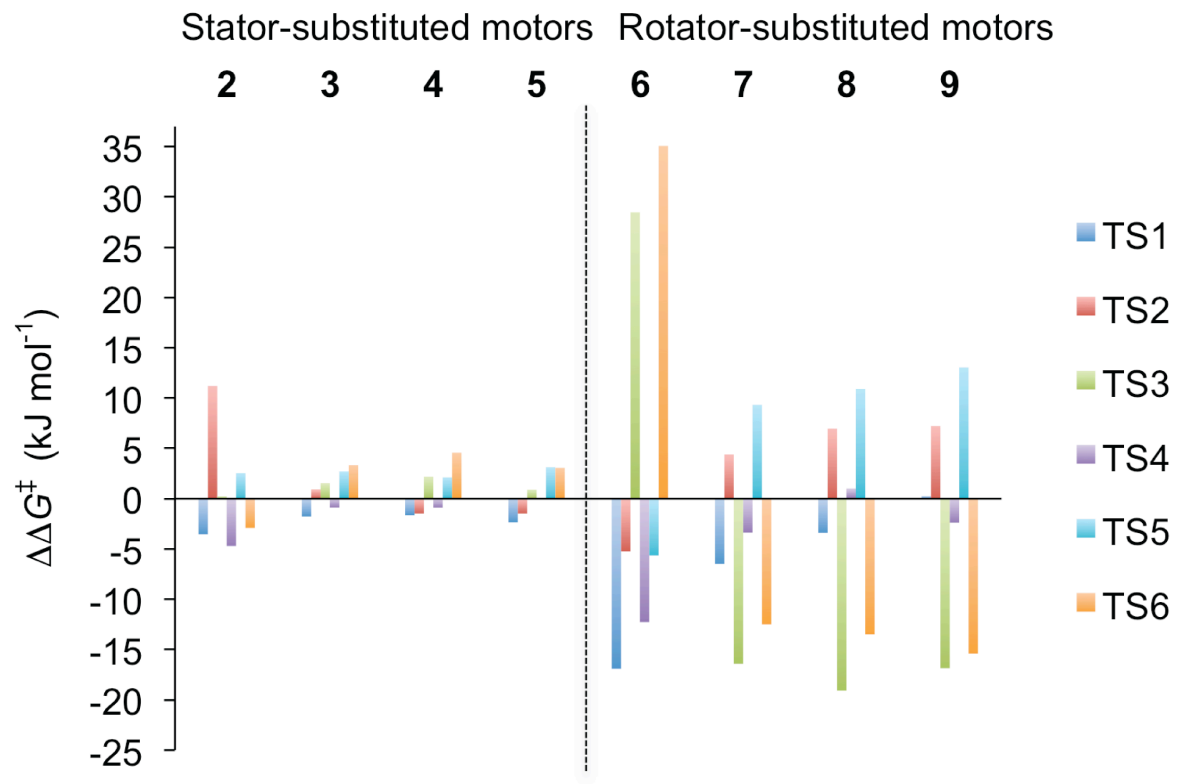

Fig. 3 Thermal free-energy barriers for motors 2-9 relative to those for motor $\mathbf{1}$.

In the mechanism for the thermal isomerizations of motor 1 presented above, the stator methoxy substituent was identified as primarily a spectator during the three steps. The rotator methyl substituent, on the other hand, was found to play a key role, both conformationally and sterically. Since the calculations suggest that the thermal isomerizations of all of motors $\mathbf{2}-\mathbf{9}$ proceed by the same mechanism as motor $\mathbf{1}$, one may therefore expect the thermal free-energy barriers to be more sensitive to the choice of rotator substituent than to the choice of stator substituent. Fig. 3 shows that this is indeed the case, with the rotator-substituted motors 6-9 exhibiting $\Delta \Delta G^{\ddagger}$ values of much larger magnitudes than the stator-substituted motors 2-5. Particularly, while none of the stator substitutions seems to appreciably lower the barriers of motor $\mathbf{1}$, all of the rotator substitutions exert a major influence on the critical TS3 and TS6 barriers.

Starting with motors 7-9, which carry a less bulky rotator substituent (methoxy, amino or hydroxyl) than motor 1 (methyl), the TS3 and TS6 barriers are $13-19 \mathrm{~kJ} \mathrm{~mol}^{-1}$ 
smaller for these systems than for motor 1 . At the same time, the TS2 and TS5 barriers are 4-13 $\mathrm{kJ} \mathrm{mol}^{-1}$ larger, and the TS1 and TS4 barriers roughly the same. Despite the increase in TS2 and TS5 barriers, it is still the TS3 and TS6 barriers that are ratedetermining for these motors. More important, however, is the observation from Table S8 that all six barriers along the thermal isomerization pathways are remarkably small for each of motors 7-9, ranging from 18 to $28 \mathrm{~kJ} \mathrm{~mol}^{-1}$ for motor 7 , from 21 to $27 \mathrm{~kJ} \mathrm{~mol}^{-1}$ for motor $\mathbf{8}$, and from 19 to $26 \mathrm{~kJ} \mathrm{~mol}^{-1}$ for motor $\mathbf{9}$. Thus, the calculations predict that the substitution of the rotator methyl group of motor $\mathbf{1}$ with a methoxy, amino or hydroxyl group would lower the rate-determining barrier by a substantial $15-17 \mathrm{~kJ} \mathrm{~mol}^{-1}$, from $43 \mathrm{~kJ} \mathrm{~mol}^{-1}$ (motor 1) to $26-28 \mathrm{~kJ} \mathrm{~mol}^{-1}$ (motors 7-9). Accordingly, we propose that such substitutions offer a route for overcrowded alkene-based motors to reach rotational frequencies well beyond the $\mathrm{MHz}$ regime that motor $\mathbf{1}$ is already capable of, ${ }^{25}$ provided that the resulting motors also show high photoisomerization quantum yields.

Continuing with motor $\mathbf{6}$, whose rotator carries a much bulkier tert-butyl group, this substitution contrarily increases the TS3 and TS6 barriers (by 29-35 $\mathrm{kJ} \mathrm{mol}^{-1}$ ) and lowers the TS2 and TS5 (by 5-6 $\mathrm{kJ} \mathrm{mol}^{-1}$ ) and TS1 and TS4 (by 12-17 $\mathrm{kJ} \mathrm{mol}^{-1}$ ) barriers relative to motor $\mathbf{1}$. As a result, although the first two steps in both half cycles of motor 6 appear to be very fast, with barriers in the $5-9 \mathrm{~kJ} \mathrm{~mol}^{-1}$ range, the $71-75 \mathrm{~kJ} \mathrm{~mol}^{-1}$ barriers of the final steps should render this system a poor candidate for a high-frequency rotary molecular motor.

The prediction that motors 7-9 are capable of reaching high rotational frequencies is corroborated by two observations in Tables S9 and S10 of the ESI, which are actually valid for all of motors 2-9. First, the net thermal isomerizations are markedly exergonic, 
which introduces a crucial driving force for the rotary motion (Table S9). Second, as to the photochemical steps of motors $\mathbf{2}-\mathbf{9}$ and associated photoisomerizations, the changes in the $\alpha$ dihedral angle during the FC relaxation of the light-absorbing anti-(M)-stable- $E$ and anti-(M)-stable- $Z$ isomers are such - decreasing for both isomers - that the $E \rightarrow Z$ and $Z \rightarrow E$ photoisomerizations would occur in a unidirectional fashion and produce rotary motion (Table S10). For one of the tentative high-frequency motors, motor 7, further computational evidence for the rotary motion is presented in Fig. S2 of the ESI.

Finally, to better understand the influence of steric bulkiness on the thermal barriers, and particularly to rationalize why the substitution of the rotator methyl group of motor $\mathbf{1}$ with a less bulky group in motors 7-9 lowers the TS3 and TS6 barriers but increases the TS2 and TS5 barriers, one can proceed as follows to define a simple geometric measure $S_{\mathrm{XY}}$ of the relevant fjord-region steric interactions in these transition structures and their preceding reactant species (full details are given in Tables S11-S14 of the ESI). First, for each atom of the rotator substituent residing within the nominal van der Waals distance ${ }^{104}$ of any atom of the stator, we attribute a value $s_{X Y}$ to the strength of each such interaction equalling the magnitude by which the distance is shorter than the corresponding van der Waals distance. Then, for each structure in question, we obtain the associated $S_{\mathrm{XY}}$ value by simply summing all $s_{\mathrm{XY}}$ values (if any) for that particular structure.

Starting with the lowering of the TS3 and TS6 barriers, the data in Table S14 indicate that, for each of motors $\mathbf{1}$ and $\mathbf{7 - 9}$, the amount of steric repulsion that can be attributed to the rotator substituent is greater in TS3 and TS6 than in the syn-(M)-stable-Z and $\operatorname{syn}$ - $(M)$-stable- $E$ species that precede these transition structures. In fact, the $S_{\mathrm{XY}}$ 
values are zero for $s y n-(M)$-stable- $Z$ and $s y n-(M)$-stable- $E$. As a consequence, more is to be gained sterically in the transition structures from replacing the methyl with a smaller group, which helps explaining why the TS3 and TS6 barriers are lowered. Turning to TS2 and TS5 and the data in Table S12, the situation is reversed in that the rotator-derived steric repulsion is smaller in these structures than in intermediate- $Z$ and intermediate- $E$. This similarly explains why the TS2 and TS5 barriers are increased when the steric size of the rotator substituent is reduced.

Furthermore, assessing the validity of using $S_{\mathrm{XY}}$ values and steric effects as indicators of barrier heights, Fig. 4a plots the TS3 and TS6 barriers for motors 1 and $\mathbf{6}^{-\mathbf{9}}$ as a function of the difference $\Delta S_{\mathrm{XY}}$ between the $S_{\mathrm{XY}}$ values for these transition structures and their syn-(M)-stable- $Z$ and $s y n-(M)$-stable- $E$ reactant species. Interestingly, this plot shows a relatively linear dependence of $\Delta G^{\ddagger}$ on $\Delta S_{\mathrm{XY}}$ (correlation coefficient of 0.92 ). Also, testing whether the variation in TS3 and TS6 barriers for these motors does indeed reflect the differences in steric bulkiness between the corresponding rotator substituents (i.e., hydroxyl, methoxy, amino, methyl and tert-butyl), rather than differences between their electronic features, Fig. $4 \mathrm{~b}$ plots the barriers as a function of the Taft steric parameters $\left(E_{\mathrm{s}}\right)$ of the substituents. ${ }^{101-103}$ Since these parameters are known to be independent of electronic features, ${ }^{105}$ the pronounced linear relationship between $\Delta G^{\ddagger}$ and $E_{\mathrm{s}}$ seems to confirm the importance of steric bulkiness in this regard (correlation coefficient of 0.99). 

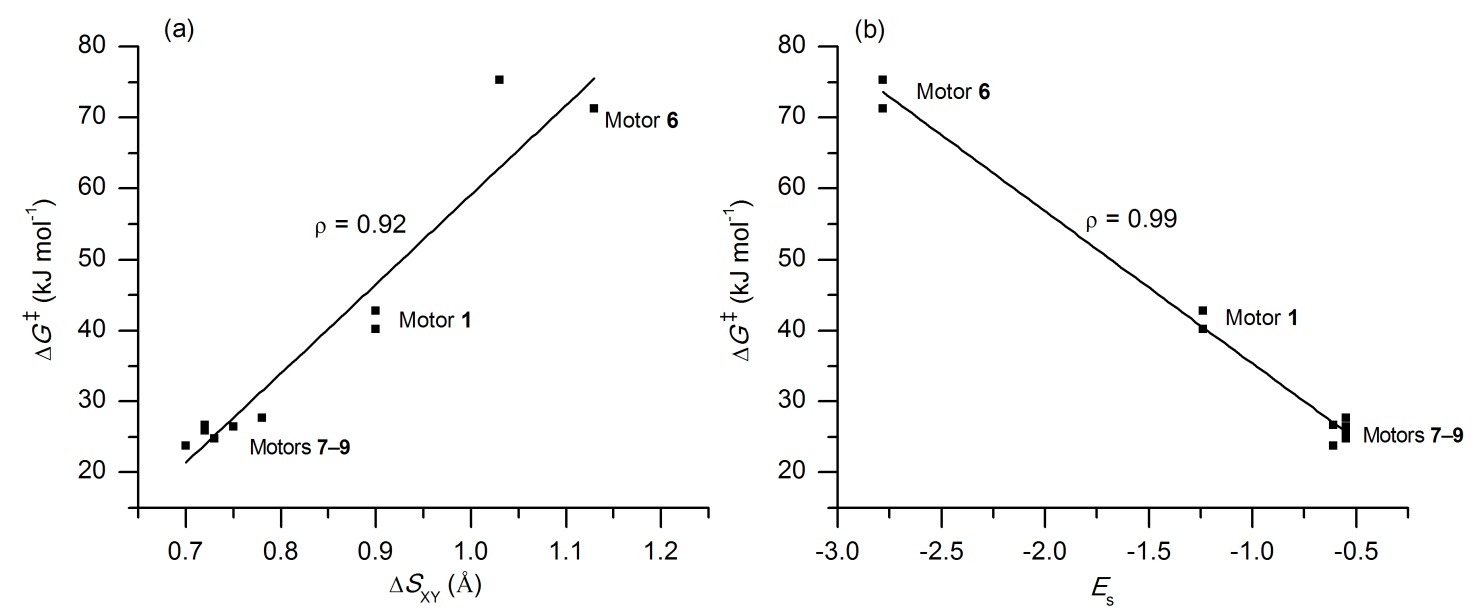

Fig. 4 (a) TS3 and TS6 thermal free-energy barriers $\left(\Delta G^{\ddagger}\right)$ for motors 1 and $\mathbf{6}^{-9}$ as a function of $\Delta S_{\mathrm{XY}}$ values. (b) TS3 and TS6 thermal free-energy barriers $\left(\Delta G^{\ddagger}\right)$ for motors 1 and $6^{-9}$ as a function of $E_{\mathrm{s}}$ values for the corresponding rotator substituents.

\section{Conclusions}

As a contribution to the ongoing development of more efficient synthetic light-driven overcrowded alkene-based rotary molecular motors, ${ }^{11,25,31,33,34,40,41}$ we have reported a systematic computational study aimed at deciphering how optimization of steric interactions may accelerate the rate-limiting thermal isomerizations of these motors. Choosing as reference a MHz-capable second-generation motor (motor $\mathbf{1})^{25}$ featuring a methoxy-substituted thioxanthene stator and a methyl-substituted cyclopenta[a]napthalenylidene rotator, we first use DFT methods to explore the thermal isomerizations of this motor.

Through these calculations, a three-step mechanism for the conversion of the photoproducts into the initial anti-(M)-stable- $Z$ and anti-(M)-stable- $E$ isomers is proposed. During the first two steps, this mechanism involves a $P \rightarrow M$ inversion of the rotator helicity and a change in orientation of the stereogenic rotator methyl substituent 
from equatorial to axial. Additionally, during the first and third steps, the stator undergoes a ring flip relative to the olefinic plane, with the latter ring flip changing the stator-rotator folding from syn to anti. This is found to be the rate-determining step of the thermal isomerizations of motor $\mathbf{1}$, and is associated with a free-energy barrier that agrees to within $6-8 \mathrm{~kJ} \mathrm{~mol}^{-1}$ with available kinetic data for both rotary half cycles. ${ }^{25}$

Next, we apply the same DFT-based computational methodology to eight new potential light-driven rotary molecular motors (motors 2-9) derived by replacing the stator methoxy and rotator methyl substituents of motor $\mathbf{1}$ with groups of varying steric bulkiness, ranging from hydroxyl to tert-butyl. From these calculations, it is predicted that the thermal isomerizations of motors 2-9 proceed by the same exact three-step mechanism as motor 1. Furthermore, it is found that rotator substitution (but not stator substitution) is a promising steric approach for accelerating the thermal isomerizations of motor 1, albeit with a much more intricate dependence on steric size than one may at first envision.

Specifically, the free-energy barrier of the third step of motor $\mathbf{1}$ is lowered by 13-19 $\mathrm{kJ} \mathrm{mol}^{-1}$ with a less bulky (motors 7-9) and increased by $29-35 \mathrm{~kJ} \mathrm{~mol}^{-1}$ with a more bulky (motor 6) rotator substituent than methyl. The barrier of the second step, on the other hand, is increased with a smaller and lowered with a larger substituent. This qualitative difference between the second and third steps in their dependence on rotator steric bulkiness can be explained by a clear difference between the steps in terms of how the amount of steric repulsion in the corresponding transition structures compares with the amount of steric repulsion in the associated reactant species. 
Despite the increase in the barrier of the second step upon decreasing the rotator steric bulkiness, it is still the third step that is rate-determining for motors 7-9. Overall, the rate-determining barriers of these motors are $15-17 \mathrm{~kJ} \mathrm{~mol}^{-1}$ smaller than that of motor 1. Accordingly, motors 7-9 appear promising candidates for moving the rotational frequencies of overcrowded alkene-based motors into new territory, provided that these motors are readily synthesizable and also show high photoisomerization quantum yields.

\section{Acknowledgments}

We acknowledge financial support from Linköping University (B.D.), the Swedish

Research Council (B.D.), the Olle Engkvist Foundation (B.D.), the Wenner-Gren Foundations (B.D. and C.F.), NSFC Grant No. 11404141 (C.F.), and grants of computing time at the National Supercomputer Centre (NSC) in Linköping.

\section{References}

1 K. Kinbara and T. Aida, Chem. Rev., 2005, 105, 1377-1400.

2 D. Stock, A. G. W. Leslie and J. E. Walker, Science, 1999, 286, 1700-1705.

3 W. R. Browne and B. L. Feringa, Nat. Nanotechnol., 2006, 1, 25-35.

4 E. R. Kay, D. A. Leigh and F. Zerbetto, Angew. Chem. Int. Ed., 2007, 46, 72-191.

5 V. Balzani, A. Credi and M. Venturi, Chem. Soc. Rev., 2009, 38, 1542-1550.

6 D. A. Leigh, J. K. Y. Wong, F. Dehez and F. Zerbetto, Nature, 2003, 424, $174-$ 179.

$7 \quad$ G. S. Kottas, L. I. Clarke, D. Horinek and J. Michl, Chem. Rev., 2005, 105, 12811376.

8 B. L. Feringa, J. Org. Chem., 2007, 72, 6635-6652.

9 J. Michl and E. C. H. Sykes, ACS Nano, 2009, 3, 1042-1048.

10 M. R. Panman, P. Bodis, D. J. Shaw, B. H. Bakker, A. C. Newton, E. R. Kay, A. M. Brouwer, W. Jan Buma, D. A. Leigh and S. Woutersen, Science, 2010, 328, $1255-1258$. 
11 T. Kudernac, N. Ruangsupapichat, M. Parschau, B. Maciá, N. Katsonis, S. R. Harutyunyan, K. H. Ernst and B. L. Feringa, Nature, 2011, 479, 208-211.

12 E. C. H. Sykes, Angew. Chem. Int. Ed., 2012, 51, 4277-4278.

13 L. Greb and J.-M. Lehn, J. Am. Chem. Soc., 2014, 136, 13114-13117.

14 T. R. Kelly, H. De Silva and R. A. Silva, Nature, 1999, 401, 150-152.

15 N. Harada, N. Koumura and B. L. Feringa, J. Am. Chem. Soc., 1997, 119, 72567264.

16 N. Koumura, R. W. J. Zijlstra, R. A. van Delden, N. Harada and B. L. Feringa, Nature, 1999, 401, 152-155.

17 B. L. Feringa, N. Koumura, R. A. van Delden and M. K. J. ter Wiel, Appl. Phys. A, 2002, 75, 301-308.

18 N. Koumura, E. M. Geertsema, M. B. van Gelder, A. Meetsma and B. L. Feringa, J. Am. Chem. Soc., 2002, 124, 5037-5051.

19 M. K. J. ter Wiel, R. A. van Delden, A. Meetsma and B. L. Feringa, J. Am. Chem. Soc., 2003, 125, 15076-15086.

20 R. A. van Delden, N. Koumura, A. Schoevaars, A. Meetsma and B. L. Feringa, Org. Biomol. Chem., 2003, 1, 33-35.

21 D. Pijper, R. A. van Delden, A. Meetsma and B. L. Feringa, J. Am. Chem. Soc., 2005, 127, 17612-17613.

22 M. K. J. ter Wiel, R. A. van Delden, A. Meetsma and B. L. Feringa, J. Am. Chem. Soc., 2005, 127, 14208-14222.

23 J. Vicario, M. Walko, A. Meetsma and B. L. Feringa, J. Am. Chem. Soc., 2006, 128, 5127-5135.

24 M. M. Pollard, M. Klok, D. Pijper and B. L. Feringa, Adv. Funct. Mater., 2007, 17, 718-729.

25 M. Klok, N. Boyle, M. T. Pryce, A. Meetsma, W. R. Browne and B. L. Feringa, J. Am. Chem. Soc., 2008, 130, 10484-10485.

26 M. Klok, M. Walko, E. M. Geertsema, N. Ruangsupapichat, J. C. M. Kistemaker, A. Meetsma and B. L. Feringa, Chem. Eur. J., 2008, 14, 11183-11193.

27 M. M. Pollard, A. Meetsma and B. L. Feringa, Org. Biomol. Chem., 2008, 6, 507512.

28 M. M. Pollard, P. V. Wesenhagen, D. Pijper and B. L. Feringa, Org. Biomol. Chem., 2008, 6, 1605-1612.

29 T. F. Landaluce, G. London, M. M. Pollard, P. Rudolf and B. L. Feringa, J. Org. Chem., 2010, 75, 5323-5325.

30 A. A. Kulago, E. M. Mes, M. Klok, A. Meetsma, A. M. Brouwer and B. L. Feringa, J. Org. Chem., 2010, 75, 666-679.

31 N. Ruangsupapichat, M. M. Pollard, S. R. Harutyunyan and B. L. Feringa, Nat. Chem., 2011, 3, 53-60.

32 J. Vachon, G. T. Carroll, M. M. Pollard, E. M. Mes, A. M. Brouwer and B. L. Feringa, Photochem. Photobiol. Sci., 2014, 13, 241-246.

33 J. Bauer, L. Hou, J. C. M. Kistemaker and B. L. Feringa, J. Org. Chem., 2014, 79, 4446-4455.

34 J. Conyard, A. Cnossen, W. R. Browne, B. L. Feringa and S. R. Meech, J. Am. Chem. Soc., 2014, 136, 9692-9700. 
35 R. A. van Delden, M. K. J. ter Wiel, M. M. Pollard, J. Vicario, N. Koumura and B. L. Feringa, Nature, 2005, 437, 1337-1340.

36 N. Katsonis, M. Lubomska, M. M. Pollard, B. L. Feringa and P. Rudolf, Prog. Surf. Sci., 2007, 82, 407-434.

37 J. Vacek and J. Michl, Adv. Funct. Mater., 2007, 17, 730-739.

38 G. London, G. T. Carroll and B. L. Feringa, Org. Biomol. Chem., 2013, 42, 34773483.

39 A. Strambi, B. Durbeej, N. Ferré and M. Olivucci, Proc. Natl. Acad. Sci. U. S. A., 2010, 107, 21322-21326.

40 R. Augulis, M. Klok, B. L. Feringa and P. H. M. van Loosdrecht, Phys. Stat. Sol. $C, 2009,6,181-184$.

41 J. Conyard, K. Addison, I. A. Heisler, A. Cnossen, W. R. Browne, B. L. Feringa and S. R. Meech, Nat. Chem., 2012, 4, 547-551.

42 P.-T. Chiang, J. Mielke, J. Godoy, J. M. Guerrero, L. B. Alemany, C. J. Villagómez, A. Saywell, L. Grill and J. M. Tour, ACS Nano, 2012, 6, 592-597.

43 R. Eelkema, M. M. Pollard, J. Vicario, N. Katsonis, B. S. Ramon, C. W. M. Bastiaansen, D. J. Broer and B. L. Feringa, Nature, 2006, 440, 163.

44 M. Klok, W. R. Browne and B. L. Feringa, Phys. Chem. Chem. Phys., 2009, 11, 9124-9131.

45 S. Grimm, C. Bräuchle and I. Frank, ChemPhysChem, 2005, 6, 1943-1947.

46 A. Kazaryan and M. Filatov, J. Phys. Chem. A, 2009, 113, 11630-11634.

47 A. Kazaryan, J. C. M. Kistemaker, L. V Schäfer, W. R. Browne, B. L. Feringa and M. Filatov, J. Phys. Chem. A, 2010, 114, 5058-5067.

48 A. Kazaryan, Z. Lan, L. V. Schäfer, W. Thiel and M. Filatov, J. Chem. Theory Comput., 2011, 7, 2189-2199.

49 F. Liu and K. Morokuma, J. Am. Chem. Soc., 2012, 134, 4864-4876.

50 M. Filatov and M. Olivucci, J. Org. Chem., 2014, 79, 3587-3600.

51 Y. Amatatsu, J. Phys. Chem. A, 2011, 115, 13611-13618.

52 Y. Amatatsu, J. Phys. Chem. A, 2012, 116, 10182-10193.

53 C. García-Iriepa, M. Marazzi, F. Zapata, A. Valentini, D. Sampedro and L. M. Frutos, J. Phys. Chem. Lett., 2013, 4, 1389-1396.

54 R. W. J. Zijlstra, W. F. Jager, B. de Lange, P. Th.van Duijnen, B. L. Feringa, H. Goto, A. Saito, N. Koumura and N. Harada, J. Org. Chem., 1999, 64, 1667-1674.

55 A. Cnossen, J. C. M. Kistemaker, T. Kojima and B. L. Feringa, J. Org. Chem., 2014, 79, 927-935.

56 G. Pérez-Hernández and L. González, Phys. Chem. Chem. Phys., 2010, 12, 1227912289.

57 C. Fang, B. Oruganti and B. Durbeej, RSC Adv., 2014, 4, 10240-10251.

58 S. Grimme, J. Comput. Chem., 2004, 25, 1463-1473.

59 J. Antony and S. Grimme, Phys. Chem. Chem. Phys., 2006, 8, 5287-5293.

60 J.-D. Chai and M. Head-Gordon, Phys. Chem. Chem. Phys., 2008, 10, 6615-6620.

61 T. Yanai, D. P. Tew and N. C. Handy, Chem. Phys. Lett., 2004, 393, 51-57.

62 C. Lee, W. Yang and R. G. Parr, Phys. Rev. B, 1988, 37, 785-789.

63 A. D. Becke, J. Chem. Phys., 1993, 98, 5648-5652. 
64

65

66

67

68

69

70

71

72

73

74

75

J. P. Perdew, K. Burke and M. Ernzerhof, Phys. Rev. Lett., 1996, 77, 3865-3868.

M. Ernzerhof and G. E. Scuseria, J. Chem. Phys., 1999, 110, 5029-5036.

Y. Zhao and D. G. Truhlar, J. Phys. Chem. A, 2006, 110, 13126-13130.

Y. Zhao and D. G. Truhlar, Theor. Chem. Acc., 2008, 120, 215-241.

A. Schäfer, H. Horn and R. Ahlrichs, J. Chem. Phys., 1992, 97, 2571-2577.

W. J. Hehre, R. Ditchfield and J. A. Pople, J. Chem. Phys., 1972, 56, 2257-2261.

V. A. Rassolov, J. A. Pople, M. A. Ratner and T. L. Windus, J. Chem. Phys., 1998, 109, 1223-1229.

V. A. Rassolov, M. A. Ratner, J. A. Pople, P. C. Redfern and L. A. Curtiss, J. Comput. Chem., 2001, 22, 976-984.

2 T. H. Dunning Jr., J. Chem. Phys., 1989, 90, 1007-1023.

3 A. V Marenich, C. J. Cramer and D. G. Truhlar, J. Phys. Chem. B, 2009, 113, 6378-6396.

74 H. P. Hratchian and H. B. Schlegel, J. Chem. Phys., 2004, 120, 9918-9924.

M. J. Frisch, G. W. Trucks, H. B. Schlegel, G. E. Scuseria, M. A. Robb, J. R. Cheeseman, G. Scalmani, V. Barone, B. Mennucci, G. A. Petersson, H. Nakatsuji, M. Caricato, X. Li, H. P. Hratchian, A. F. Izmaylov, J. Bloino, G. Zheng, J. L. Sonnenberg, M. Hada, M. Ehara, K. Toyota, R. Fukuda, J. Hasegawa, M. Ishida, T. Nakajima, Y. Honda, O. Kitao, H. Nakai, T. Vreven, J. A. Montgomery, Jr., J. E. Peralta, F. Ogliaro, M. Bearpark, J. J. Heyd, E. Brothers, K. N. Kudin, V. N. Staroverov, R. Kobayashi, J. Normand, K. Raghavachari, A. Rendell, J. C. Burant, S. S. Iyengar, J. Tomasi, M. Cossi, N. Rega, J. M. Millam, M. Klene, J. E. Knox, J. B. Cross, V. Bakken, C. Adamo, J. Jaramillo, R. Gomperts, R. E. Stratmann, O. Yazyev, A. J. Austin, R. Cammi, C. Pomelli, J. W. Ochterski, R. L. Martin, K. Morokuma, V. G. Zakrzewski, G. A. Voth, P. Salvador, J. J. Dannenberg, S. Dapprich, A. D. Daniels, Ö. Farkas, J. B. Foresman, J. V. Ortiz, J. Cioslowski and D. J. Fox, Gaussian 09, Revision D.01, Gaussian, Inc., Wallingford CT, USA, 2009.

76 P. U. Biedermann, J. J. Stezowski and I. Agranat, Eur. J. Org. Chem., 2001, 1534.

77 E. Runge and E. K. U. Gross, Phys. Rev. Lett., 1984, 52, 997-1000.

78 R. Bauernschmitt and R. Ahlrichs, Chem. Phys. Lett., 1996, 256, 454-464.

79 M. E. Casida, C. Jamorski, K. C. Casida and D. R. Salahub, J. Chem. Phys., 1998, 108, 4439-4449.

80 R. E. Stratmann, G. E. Scuseria and M. J. Frisch, J. Chem. Phys., 1998, 109, 82188224.

81 F. Furche and R. Ahlrichs, J. Chem. Phys., 2002, 117, 7433-7447.

82 M. A. L. Marques and E. K. U. Gross, Annu. Rev. Phys. Chem., 2004, 55, 427455.

83 M. Chiba, T. Tsuneda and K. Hirao, J. Chem. Phys., 2006, 124, 144106/1144106/11

84 M. E. Casida, J. Mol. Struct. (THEOCHEM), 2009, 914, 3-18.

85 M. E. Casida and M. Huix-Rotllant, Annu. Rev. Phys. Chem., 2012, 63, 287-323.

86 S. Hirata and M. Head-Gordon, Chem. Phys. Lett., 1999, 314, 291-299.

87 Y.-L. Wang and G.-S. Wu, Int. J. Quantum Chem., 2008, 108, 430-439. 
88 C. M. Isborn, N. Luehr, I. S. Ufimtsev and T. J. Martínez, J. Chem. Theory Comput., 2011, 7, 1814-1823.

89 A. Chantzis, A. D. Laurent, C. Adamo and D. Jacquemin, J. Chem. Theory Comput., 2013, 9, 4517-4525.

90 O. Christiansen, H. Koch and P. Jørgensen, Chem. Phys. Lett., 1995, 243, 409418.

91 R. Ahlrichs, M. Bär, M. Häser, H. Horn and C. Kölmel, Chem. Phys. Lett., 1989, 162, 165-169.

92 TURBOMOLE V6.3 2011, a development of University of Karlsruhe and Forschungszentrum Karlsruhe GmbH, 1989-2007, TURBOMOLE GmbH, since 2007; available at: http://www.turbomole.com (accessed February 3, 2015).

93 M. Olivucci and A. Sinicropi, in Theoretical and Computational Chemistry: Computational Photochemistry, ed. M. Olivucci, Elsevier, Amsterdam, 2005, vol. 16, ch. 1, pp. 1-33.

94 B. G. Levine, C. Ko, J. Quenneville and T. J. Martínez, Mol. Phys., 2006, 104, 1039-1051.

95 A. Kazaryan, J. Heuver and M. Filatov, J. Phys. Chem. A, 2008, 112, 1298012988.

96 W. R. Browne, M. M. Pollard, B. de Lange, A. Meetsma and B. L. Feringa, J. Am. Chem. Soc., 2006, 128, 12412-12413.

97 D. R. Glowacki, C. H. Liang, S. P. Marsden, J. N. Harvey and M. J. Pilling, J. Am. Chem. Soc., 2010, 132, 13621-13623.

98 L. M. Goldman, D. R. Glowacki and B. K. Carpenter, J. Am. Chem. Soc., 2011, 133, 5312-5318.

99 S. A. Adelman, J. Phys. Chem. A, 2010, 114, 5231-5241.

100 D. R. Glowacki, C. H. Liang, C. Morley, M. J. Pilling and S. H. Robertson, J. Phys. Chem. A, 2012, 116, 9545-9560.

101 R. W. Taft Jr., J. Am. Chem. Soc., 1952, 74, 3120-3128.

102 R. W. Taft Jr., J. Am. Chem. Soc., 1953, 75, 4231-4238.

103 M. B. Smith and J. March, in March's Advanced Organic Chemistry, John Willey \& Sons, New York, 2007, Sixth Edit., ch. 9, pp. 410-411.

104 A. Bondi, J. Phys. Chem., 1964, 68, 441-451.

105 M. Charton, J. Am. Chem. Soc., 1969, 91, 615-618. 


\section{Table of contents: Graphical and textual abstract}

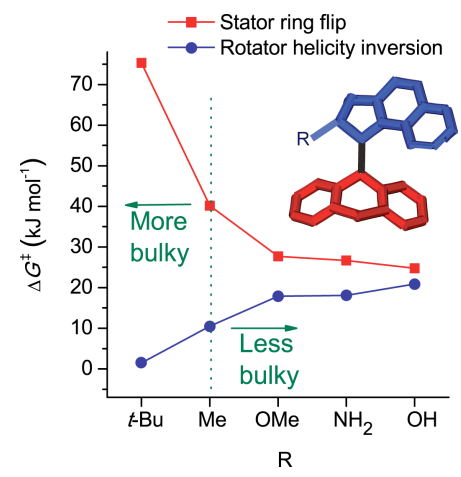

By tuning the steric bulkiness of the stereogenic substituent, the rate-determining thermal free-energy barrier of an already $\mathrm{MHz}$-capable rotary molecular motor can be reduced by a further $15-17 \mathrm{~kJ} \mathrm{~mol}^{-1}$. 